\title{
University training in energy efficiency to respond to European EPBD objectives. USE Efficiency Project
}

\author{
Elisa Peñalvo-López ${ }^{a}$, Francisco-Javier Cárcel-Carrascob, Joaquín Montañana- \\ Romeu $^{c}$, Vicente León-Martínez ${ }^{\mathrm{d}}$ \\ Universitat Politècnica de València, Valencia, Spain, \\ elpealpe@upvnet.upv.es ${ }^{\mathrm{a}}, \underline{\text { fracarc1@ecsa.upv.es }}^{\mathrm{b}}$, jmontanana@die.upv.es $^{\mathrm{c}}$, vleon@die.upv.es ${ }^{\mathrm{d}}$.
}

\begin{abstract}
Energy efficiency in buildings is one of the main challenges in EU policy, since it is difficult to find common strategies and policies among Member States. This article describes the USE Efficiency project, an initiative to create a common training framework for energy efficiency systems in buildings based on the Energy Performance Building Directive (EPBD), through university actions. Universities and students are proposed as shining examples both for energy efficiency solutions and for energy efficiency behaviour. Moreover, involving university students guarantees acting on closest future market players and most convincing actor in diffusion of public opinions.
\end{abstract}

The project aims to improve energy efficiency in university buildings and to establish training program for students around European countries. In fact, this activity involves 9 Universities (Technology Faculties and Faculties of Engineering) and 4 technological and market players from widespread countries in EU.

This paper describes this innovative training initiative, which focuses on students as main actors, working and interacting together with professors and technicians in order to improve energy efficiency in their educational centres.

Keywords: University students training, Energy Performance Building Directive (EPBD), Energy Performance Assessment (EPA), energy efficiency, buildings; European project. 
University training in energy efficiency to respond to European EPBD objectives. USE Efficiency Project.

\section{Introduction}

Approximately $40 \%$ of the energy consumption in EU comes from Buildings, which corresponds to $36 \%$ of the $\mathrm{CO}_{2}$ emissions in the European Union. This is mainly due to the fact that a large percentage of the buildings (36\%) are over 50 years old (35\%) with high energy inefficiencies (Azari et al 2018) (Escrivá et al. 2011). Moreover, renovation of building stock is not very frequent, only $1-2 \%$ of the buildings are renovated each year in Europe. Therefore, there is a significant potential in energy reduction from existing buildings.

Electrical engineers are the next future market players. They will play a key role in transforming the actual building stock into smart and energy efficiency construction. However, electrical engineers need to be properly prepared in order to successfully tackle this important challenge. A holistic approach in the educational programme is needed, integrating the different perspectives from other disciplines (Egemen et al. 2015).

In this context, USE Efficiency is an interinstitutional and interdisciplinary educational programme implemented in nine European Universities targeting energy efficiency in buildings. The educational programme effectively links professors, students, engineers and industry experts, creating a unique learning experience.

Main objective of USE Efficiency is training university students in a holistic and practical approach, improving their skills in energy efficiency in buildings while increasing energy performance of university buildings and removing non-technological barriers associated to the implementation of energy efficiency measures in buildings.

The following section provides a general overview of the USE Efficiency methodology. Then, it is provided the simulation carried out as the shining example selected at Universitat Politècnica de València (UPV). Finally, it is provided the practical monitoring training procedure defined in the context of the project. .

\section{Building data}

The methodology focused on developing first level analysis of existing building more than new ones, trying to identify the potential spots for energy reduction in order to optimize energetically its consumption. Initially it was carried out the building simulation of the School of Engineering at UPV. Then, it was measured the energy consumption in illumination, ventilation, heat and power systems, and any other electric consumption of the building. Moreover, a basic procedure for new and renovated buildings resulting in an energy efficiency certification was implemented based on the Spanish Real Decreto $47 / 2007$. The energy efficiency certificate is also accompanied by an energy efficiency 
label, which associates each building with an energetic class according to a scale of seven colours. This scale is based on carbon dioxide $\left(\mathrm{CO}_{2}\right)$ emissions and energy consumption of the building installations, such as heating, refrigeration, hot water healthcare and lighting.

As mentioned, the selected building is the School of Industrial Engineering (Building 5N), which is organised in offices and classrooms, including computer labs and a cellar parking. Practical work of students began with the first level audit, a macro analysis for studying the energy data of the university building consumption and use.

During the information gathering process, engineering students collected basic documentation from the building such as year of construction, main activity, dimensions and AutoCAD drawings to better identify the building set up as well as installed equipment.

Next, it is showed the information of the selected building, together with the Auto-CAD drawings:

Table 1. 5N -School of Industrial Engineering Building Data

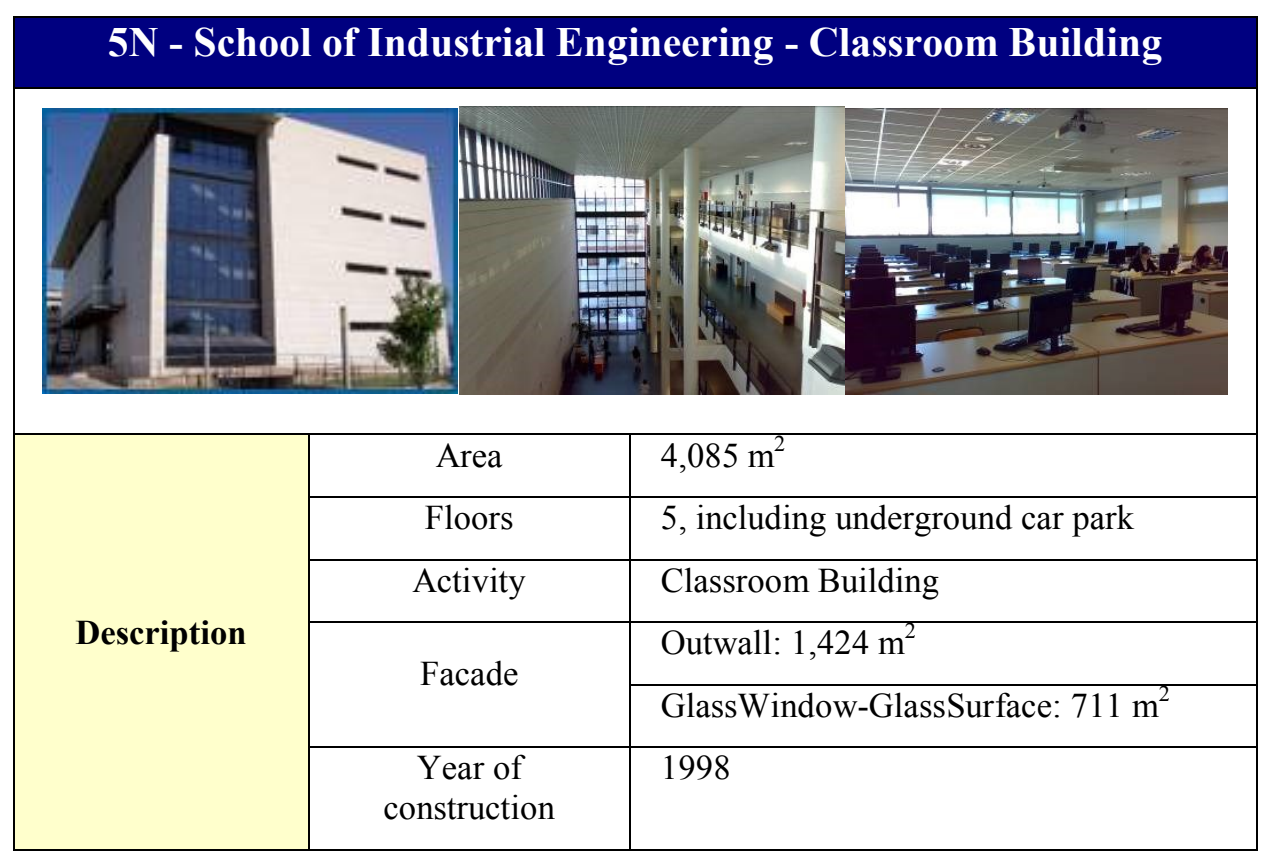


University training in energy efficiency to respond to European EPBD objectives. USE Efficiency Project.

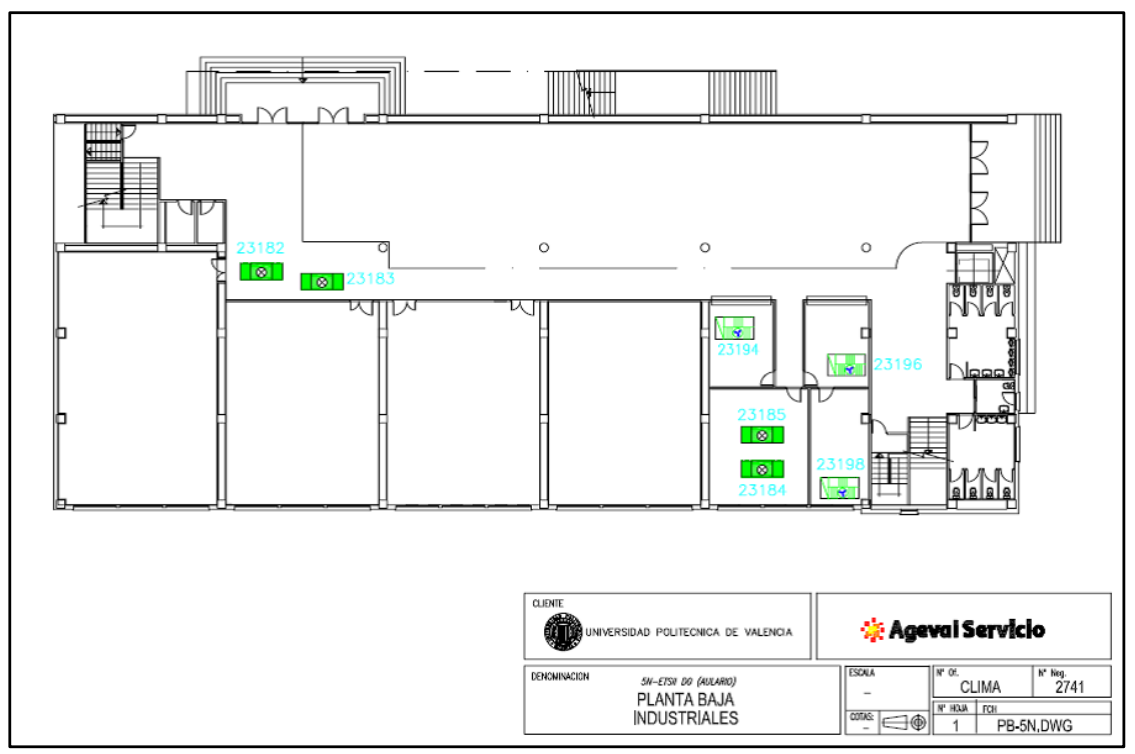

Fig. 1- Building $5 N$ - Basement Floor

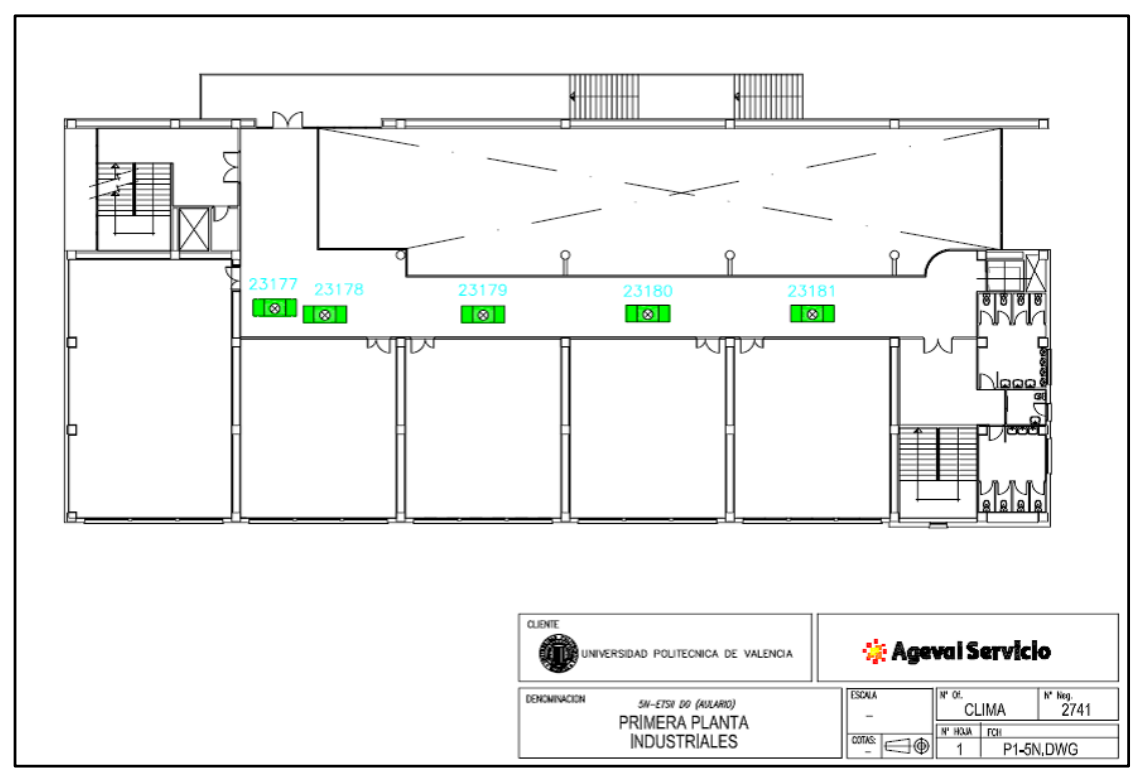

Fig. 2- Building $5 N$ - First Floor 


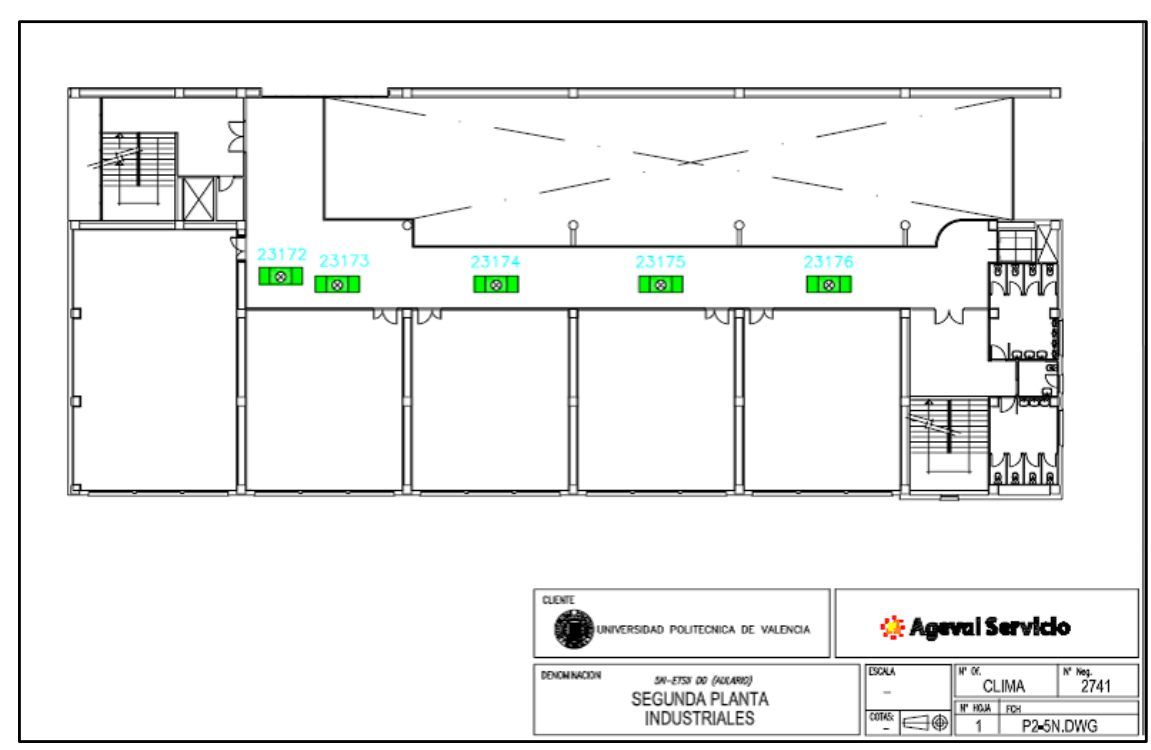

Fig. 3- Building $5 N$ - Second Floor

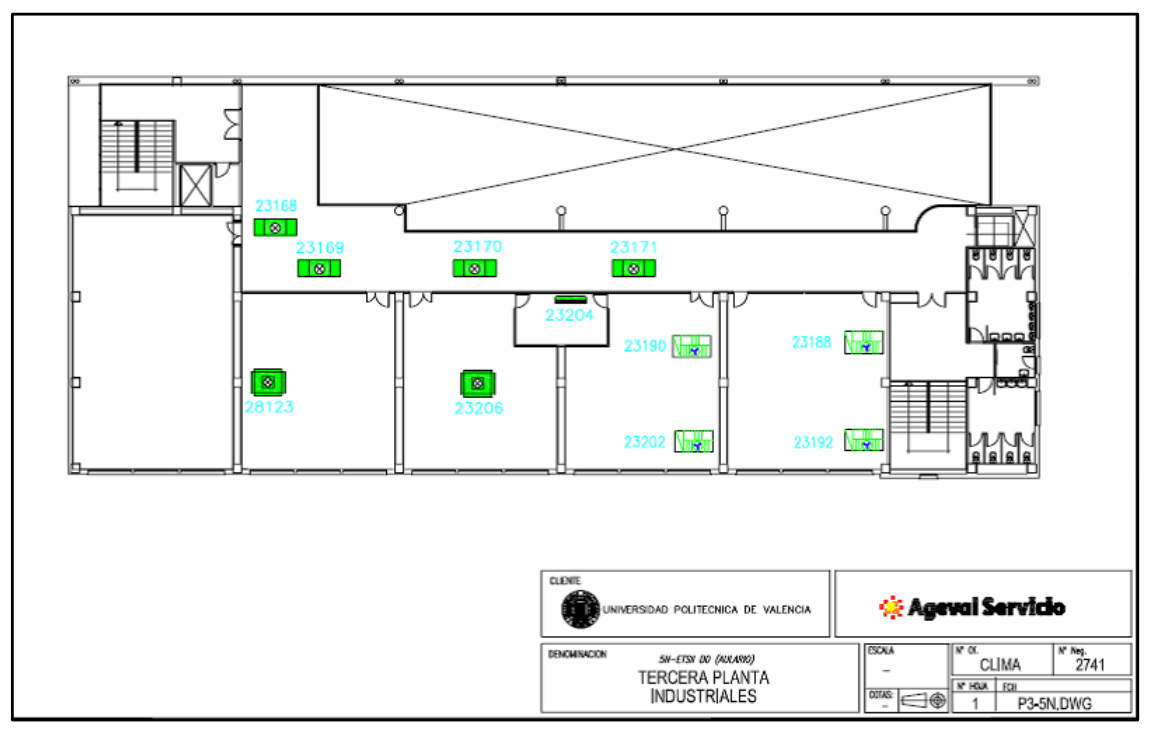

Fig. 4- Building 5N - Third Floor 


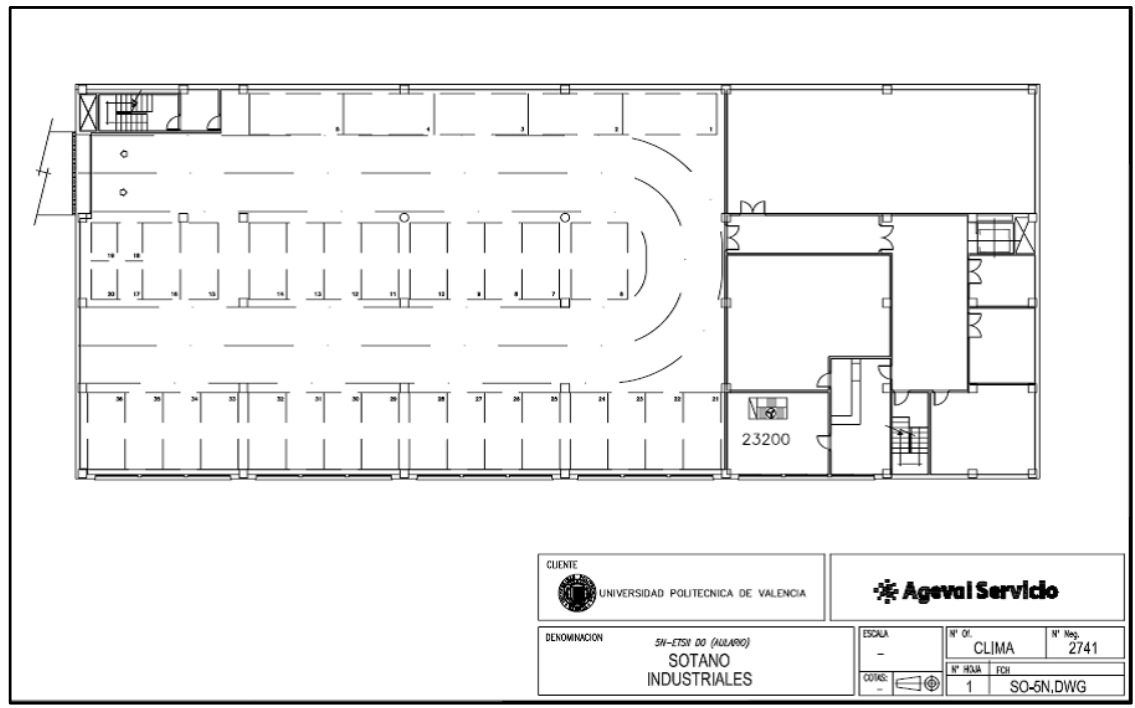

Fig. 5- Building $5 N$ - Cellar Floor - Parking

\section{Monitored power data}

Next stage of the educational programme included a period of energy data collection. Energy Data Management system was installed at the end of 2008, beginning a data adquisition period from 01/01/2009 until 31/12/2009. During the monitoring period, electrical variables were observed, since no other fuel types were used.

Results from the energy monitoring period provided power consumption data from lighting, ventilation, HVAC, ventilation, and other small uses. Based on this information, it was determined the power daily profile for summer and winter. 
Table 2. 5N -School of Industrial Engineering Building Data

\section{N - School of Industrial Engineering - Classroom Building}

\begin{tabular}{|c|c|c|c|}
\hline \multirow{17}{*}{$\begin{array}{c}\text { Installed } \\
\text { Power }\end{array}$} & \multirow{5}{*}{ TOTAL $35.0 \mathrm{~kW}$} & Area & $\begin{array}{c}\text { Total } \\
\text { Power } \\
\text { kW }\end{array}$ \\
\hline & & Classroom & 17.5 \\
\hline & & Office & 1.3 \\
\hline & & Bathroom & 2.3 \\
\hline & & Passage & 13.9 \\
\hline & \multirow{6}{*}{ TOTAL $155.0 \mathrm{~kW}$} & Type & Units \\
\hline & & Splits & 11 \\
\hline & & Air Handers & 18 \\
\hline & & Air-Water Chillers & 1 \\
\hline & & Air-Water Chillers-Heat & 1 \\
\hline & & Pumps & 7 \\
\hline & \multirow{6}{*}{ TOTAL $51.0 \mathrm{~kW}$} & \multirow[t]{2}{*}{ Type } & Units \\
\hline & & & 166 \\
\hline & & Water coolers & 5 \\
\hline & & Elevators & 1 \\
\hline & & Photocopiers & 1 \\
\hline & & Vending Machines & 5 \\
\hline
\end{tabular}






\section{Energy Certification Label}

Energy Certification Rating was estimated using the official software CALENER, a tool promoted by the Spanish Minister of Industry, Tourism and Trade trough the IDAE (Institute of Diversification and Saving of Energy) in order to comply with the Basic Procedure for Energy Performance Certification. Building model and results of the energy certification are shown in the next figures, providing information regarding the energy efficiency level of the building, energy consumption by uses and $\mathrm{CO}_{2}$ emissions. 


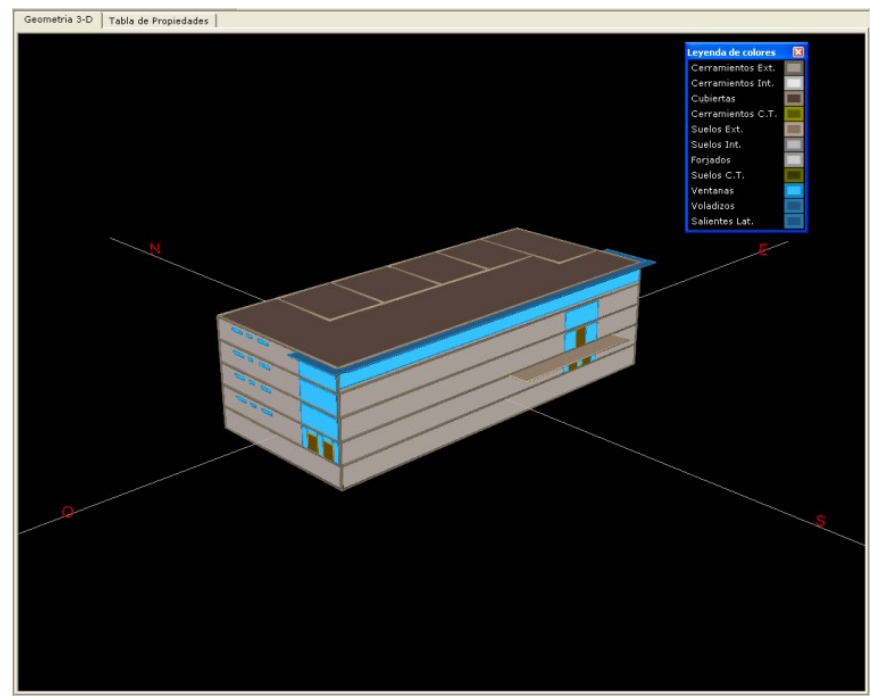

Fig. 6. Geometrical definition of the building modelled with Calener

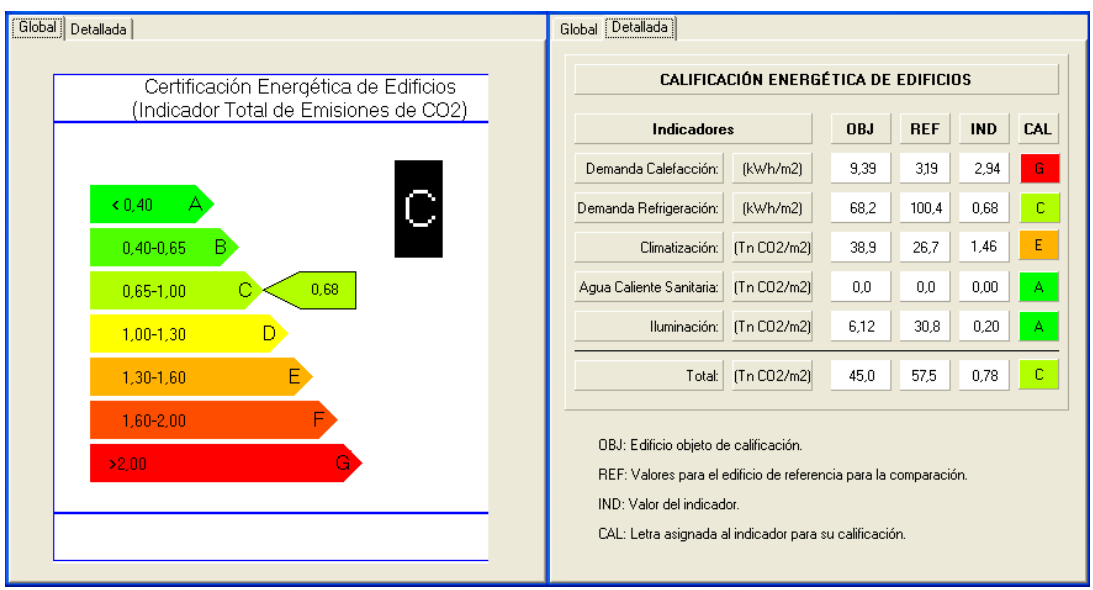

Fig. 7. Energy qualification label 


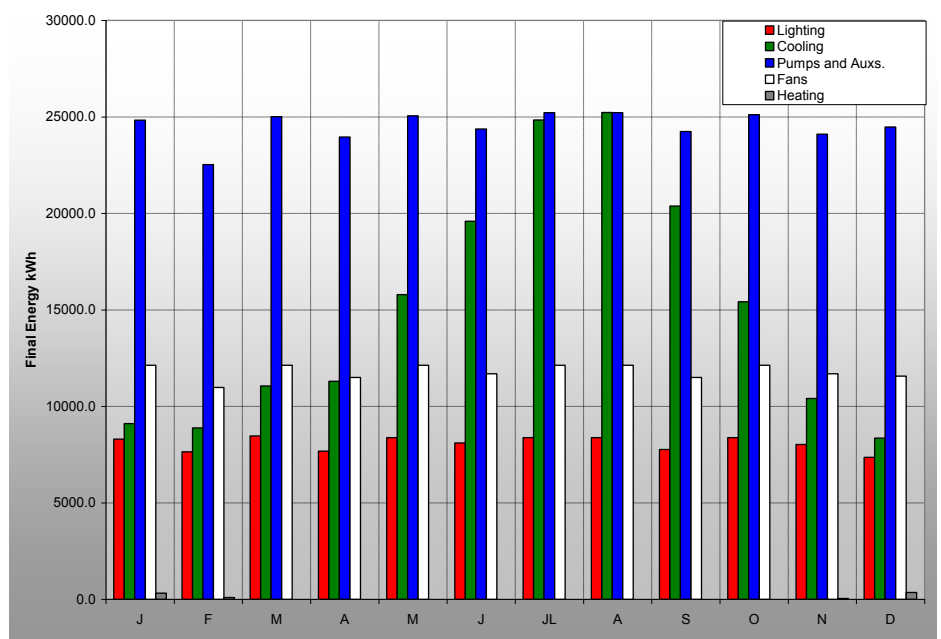

Fig. 8. Final energy consumption by uses resulting from simulation



Fig. 9. $\mathrm{CO}_{2}$ emissions by uses resulting from simulation 


\section{Monitoring Training Programme}

This section describes the energy training programme resulting from the project. It defines the energy monitoring structure based on several steps. This training agenda was implemented at Universitat Politècnica de València (UPV) as an example of its implementation.

\section{Step 1: Energy Policy}

Energy monitoring must be organised based on Spanish and European regulations. Following main European and Spanish directives of reducing energy consumption in buildings, the programme shall define the monitoring training plan according to the policy context, including the local policy framework with the monitored organisation. In the case of Universitat Politècnica de València, the following commitments were agreed:

- A statement of commitment of the university responsible, which responds to a public declaration of commitment to energy efficiency policy.

- An agreement outlining the long term and short term goals and the categorised energy policy objectives necessary to achieves goals.

- Define the university economical support to implement the energy audits and energy efficiency strategies, as well as creating a management structure, roles and responsibilities.

\section{Step 2: Identify and analysis}

Spanish minister recommends to carry out building audits based on the "Código Técnico de la Edificación (CTE)" regulation, which normalizes the technical aspects of energy efficiency assessment in public and private buildings, considering energy demand limitations, thermal facilities efficiency, lighting installations efficiency, contribution of solar energy generation for thermal needs, and photovoltaic generation for electrical demand contribution.

Following these recommendations, energy consumption audits are carried out based on questionnaires to different demand profiles. Additionally, an energy monitoring system should be installed in the selected buildings in order to identify potential energy savings. This approach allows focusing on a dynamic method based on continuous benchmark energy performance instead to a static best practice measures.

As far as UPV, the scope of the energy audits was beyond the requirements of Spanish regulations, focusing in 7 main objectives: 
- Energy consumption

- Lighting

- Energy certification

- Heat power

- Isolation

- Air conditioning

- Water heat

\section{Step 3: Plan and Organise}

The objective of UPV energy efficiency approach was based on the identification of several energy efficiency actions without compromising user's comfort. To accomplish this, it was required the creation of an Energy Committee, whose tasks include the following activities:

- Analysis of energy provisions and renewable generation alternatives.

- Continuous monitoring of consumption and definition of energy ratios based on different building characteristics.

- Definition of training courses and/or awareness campaigns to inform the university community, providing them with specific measures to be easily accomplished according to their energy demand profiles.

- Definition of an Energy Programme with large, medium and short term goals, identifying energy activities for each term and the necessary investments for improving their energy performance.

- Evaluate energy labels for each building demand profile, based upon the national Building Energy Efficiency certification.

- Develop an Energy Control and Follow-Up Programme to monitor the evolution of the energy plan and detect any potential deviation. In case adjustments to the plan are necessary, the Energy Committee should study the alternatives and implement the modifications.

- Finally, the Energy Committee should promote the Energy Programme and its achievement in the university throughout an Energy Communication newsletter.

\section{Step 4: Implementation}

Finally, the implementation of a Energy Management System should be installed at the university in order to monitor energy data and assist the Energy Responsible in the decision making process. This may be complemented with periodic energy audits in all building to identify new energy efficiency strategies. 
Furthermore, the implementing of the Energy Programme has to encompass raising awareness, in order to overcome non-technical barriers. Energy awareness may be promoted by:

- An official launch of the Energy Programme at the University

- Efficiency poster campaigns and energy efficiency ideas competitions for students and staff.

- An energy website with information about energy analysis, performance and savings.

- Student participation in energy efficiency projects.

- Providing lectures to students and staff on specific energy efficient technologies used and energy savings achieved.

\section{Step 5: Control and Monitoring}

Finally, a continuous implementation of the Energy Programme helps to create a historic database. This information may be used for a continuous improvement process.

\section{Acknowledgments}

This initiative responds to a common effort between 9 European universities and 3 market players, funded by the "Universities and Students for Energy Efficiency (USE Efficiency)" project (Ref. CIP-IEE-2008). The work was completed by the Institute for Energy Engineering located at the Universitat Politècnica de València. The authors deeply thanks the Universitat Politècnica de Valencia and all the organizations involved in this project for their support and, specially, to the European Commission for their funding provision.

\section{References}

Akmençe, A.E., Akpinar, B., Akmençe, E. (2015). New Horizons In Education Through Holistic Approach The Journal of International Lingual, Social and Educational Sciences, (1).

Azari R., Abbasabadi N. (2018). Embodied energy of buildings: A review of data, methods, challenges, and research trends. Elsevier, Energy and Buildings, 168, pp. 225-235.

Carpio, M., Martín-Morales, M., Zamorano, M. (2015). Comparative study by an expert panel of documents recognized for energy efficiency certification of buildings in Spain. Energy and Buildings, 99, pp. 98-103.

Chengchu, Y., Shengwei, W., Fu. X. (2012). A simplified energy performance assessment method for existing buildings based on energy bill disaggregation. Energy Build., 55, pp. 563-574. 
University training in energy efficiency to respond to European EPBD objectives. USE Efficiency Project.

Costa, A., Keane, M.M., Torrens, J.I., Corry, E. (2013). Building operation and energy performance: monitoring, analysis and optimization toolkit Applied Energy, 101, pp. 310-316.

Escrivá-Escrivá G, Álvarez-Bel C., Peñalvo-López E. (2011). New indices to assess building energy efficiency at the use stage. Elsevier, Energy and Buildings, 43, pp. 476-484

Geng Y., Wenjie, J., Borong, L., Jiajie, H., Yingxin, Z. (2018). Building energy performance diagnosis using energy bills and weather data. Energy and Buildings, Vol 172, pp 181-191

Herrando, M., Cambra, D., Navarro, M., De la Cruz, L., Zabalza, I. (2016). Energy Performance Certification of Faculty Buildings in Spain: The gap between estimated and real energy consumption. Energy Conversion and Management, Volume 125, pp 141-153.

Lee, W.L., Yik W.H., Burnett, J. (2003). A method to assess the energy performance of existing commercial complexes. Indoor Built Environment., 12 (5), pp. 311-327

Mavromatidis, G., Acha, S., Shah. N. (2013). Diagnostic tools of energy performance for supermarkets using artificial neural network algorithms. Energy Building, 62, pp. 304-314 